\title{
OPTIMIZING SHADING DEVICES THROUGH THE SHADING EFFECT OF SURROUNDING BUILDINGS
}

\author{
Alifiano Rezka Adi ${ }^{1^{*}, J^{\prime}}$ atmika Adi Suryabrata ${ }^{2}$, Eugenius Pradipto ${ }^{2}$ \\ ${ }^{1}$ Department of Art and Islamic Architecture, Faculty of Ushuluddin and Humanities, UIN Walisongo Semarang \\ UIN Campus 2, Prof. Dr. Hamka Street Km.1, Tambakaji, Ngaliyan, Semarang 50181, Phone 0247601294 \\ ${ }^{2}$ Department of Architecture and Planning, Faculty of Engineering, UGM Yogyakarta \\ Grafika Street No.2 UGM Campus, Yogyakarta 55281, Phone 0274542973 \\ *Corresponding author; Email: alifiano.rezka@walisongo.ac.id
}

\begin{abstract}
This study focuses on measuring the shading effect of surrounding buildings on the thermal performance of office buildings in Jakarta. It is compared with the shading effect of shading devices to optimize its use. This study uses EnergyPlus program to simulate a hypothetical 3x3block. The results showed that the H/W ratio has greater influence on building thermal performance than the surrounding building envelopes. With $\mathrm{H} / \mathrm{W}$ ratio 2,7, the shading effect of surrounding buildings will be equivalent to $1,2 \mathrm{~m}$ shading with an effective shadow angle of more than $36^{\circ}$. For example, in a 10 floor building, the use of $1,2 \mathrm{~m}$ shading is not required until the 8th floor based on the shadow angle in $\mathrm{H} / \mathrm{W}$ ratio 2,7. At a smaller angle, the shading effect of surrounding buildings will be equal to the shading effect of shading devices with a width of less than $1,2 \mathrm{~m}$.
\end{abstract}

Keywords: Thermal performance; surrounding buildings; Jakarta; shading devices; effective shadow angle.

\section{INTRODUCTION}

In a dense urban environment, a building doesn't stand alone but relates to the surrounding buildings. Currently in big cities, building density can greatly affect the incident radiation of the building envelopes and building thermal performance. Nevertheless, in the construction of high-rise buildings, consideration is seldom given to the surrounding buildings as factors that affect the building envelope design. The envelope components such as window to wall ratio (WWR), glass material, wall material, or shading elements are generally designed to achieve thermal comfort in the worst climatic conditions, where solar radiation is calculated during the daytime assuming no barriers outside the building.

A different height/width ratio (H/W ratio) can affect the level of energy consumption and heat gain at each level of the building in a dense urban area (Andersen \& Sattrup, 2011). If the surrounding buildings are considered to be an influential factor, the building facade design can be varied at each level as each will have a different thermal condition based on the effects of the surrounding buildings. Currently, the high rise building has relatively homogenous facades on each floor. Shading devices or windows are fully applied to the facade to support the appearance of the building. This indicates that the surrounding buildings are not considered in the facade design process in relation to thermal conditions.

Consideration of the surrounding buildings will encourage more effective shading devices according to differing thermal requirements at each level. There- fore, it is necessary to research building design in dense urban environments with specific parameters to determine the level of shading effect of surrounding buildings in influencing building thermal performance. The shading effect of surrounding buildings can then be useful in assisting architects to design more effective building envelopes. Based on these issues, the key questions in this study are:

1. How great is the impact of the shading effect of surrounding buildings on a building's thermal performance?

2. How does the shading effect of surrounding buildings affect the building envelope designs?

\section{PREVIOUS STUDIES}

In a tropical area, such as Indonesia, the intensity of solar radiation can trigger high building energy, mainly due to the cooling load (Kwong \& Ali, 2011). The building envelope affects the level of energy consumption in buildings (Granadeiro, et al., 2013). In the pursuit of greater energy efficiency in buildings, envelope engineers generally use shading devices to reduce heat gain in a building (Kirimtat, et al., 2016). The energy efficiency of buildings in big cities like Jakarta can save energy by 30-50\% through use of a few strategic measures, such as the use of solar shading, which can contribute to the greatest energy savings when compared with other strategies (Shrader \& Sayyed, 2012).

Even so, energy performance in buildings is not only influenced by internal factors, but also external factors such as the urban context (Hachem, Athienitis, 
\& Fazio, 2012). The buildings' facades, temperatures and their shadowing effects in an urban environment affect not only the local climate, but also the energy requirements of the building (Allegrini, Dorer, \& Carmeliet, 2015). The pattern of energy consumption of buildings located in the center of a high density area is highly dependent on the surrounding urban environment, compared to low density areas where the building energy consumption pattern is similar to that of an isolated building (Srebric, Heidarinejad, \& Liu, 2015). Building design that fits the neighborhood context can improve both energy consumption in buildings and energy for transportation (Marique \& Reiter, 2014). A shadowing effect, produced by surrounding buildings with a number of floors and building density, will affect the reduction of a building's energy consumption in a variety of ways (Ascione, et al., 2013).

A new experimental study of the design of neighboring building envelopes has found that a bioinspired retro-reflective building envelope can reduce the energy required for cooling (Han, Pisello, \& Taylor, 2015). The reflectivity of urban canyons plays an important role which needs to be taken into account when designing low energy buildings in dense cities (Andersen \& Sattrup, 2011). Energy calculations made ignoring the reflectivity of surrounding building facades have relatively smaller errors, of around $0-11 \%$, than those which ignore the urban context altogether at around 8-31\% (Samuelson, et al., 2016). At the same floor area ratio (FAR), the variation of density factors such as building coverage ratio (BCR) and building heights produce different incident radiation levels of up to $30 \%$ depending on the calculation method (Lee, Lee, \& Lee, 2016).

This study tries to analyze the factors of surrounding building envelope designs with different $\mathrm{H} / \mathrm{W}$ ratios. Furthermore, the effectiveness of surrounding buildings in affecting building thermal performance is measured by comparison with the shading device effect in the case of stand-alone buildings. The effectiveness levels gained from this comparison can be a reference for architects in designing high rise building facades that take into consideration the presence of surrounding buildings.

\section{METHODOLOGY}

The research was conducted using a quantitative method with an experimental research strategy and simulation using EnergyPlus software. The building is assumed to be in the middle of the city which has a grid space pattern (Steiner \& Butler, 2007). This pattern was chosen by considering the common pattern of urban space in Indonesia. The simulated building is a hypothetical $3 \times 3$ block consisting of a central building as a focus, and surrounding buildings as external factors. This pattern is a form of urban block that Martin and March have studied as consideration for researchers who are interested in thermal performance issue in the urban scale (Sanaieian, et al., 2014).

The thermal performance of central building envelope is depicted in overall thermal transfer value (OTTV). EnergyPlus doesn't have an algorithm to calculate the OTTV value directly, so that the calculation is done by determining the external heat gain of the building envelope from the wall conduction, glass conduction, and solar radiation through the glass. Those are defined as Opaque Surface Inside Face Conduction and Window Transmitted Solar in EnergyPlus output. The value is then divided by the building envelope surface area to get the OTTV value. The simulation period is set for 365 days where the daily external heat gain is calculated from 7 am to $6 \mathrm{pm}$ according to SNI 6389-2011 related to Energy Conservation of Building Envelope in Buildings. Variables in the central building as WWR, glass type, and wall type are of a fixed value. They are adjusted to get OTTV of $45 \mathrm{~W} / \mathrm{m}^{2}$ in conditions of stand-alone buildings (Jakarta Governor Regulation).

The central building OTTV is viewed based on the influence of each variable of the surrounding buildings around such as glass percentages, glass reflectance, wall reflectance, and $\mathrm{H} / \mathrm{W}$ ratio. The differences in OTTV values for each surrounding buildings variable are then explained by simulating the surface incident radiation of the central building. EnergyPlus describes the radiation sources in direct solar radiation, sky diffuse radiation, reflected radiation on the ground, reflected radiation in the sky, and reflected solar radiation from the other surfaces. The greater the radiation per area obtained by the central building envelope will affect the bigger OTTV value.

The thermal simulation results will produce the most influential variable of the surrounding buildings for the thermal performance of central building. To find out the shading effectiveness of surrounding buildings, a comparative test was carried out between the shading effects of the surrounding buildings and the shading effect of shading devices on a single building condition. The most influential variable from surrounding buildings are used as parameters to determine the surface incident radiation of the central building. Comparisons of the shading effect are then visualized in the effective shadow angle. It describes the angle that represents the equality between shading effect of the surrounding buildings and shading effect of the shading devices at a certain width. 
These simulations use Jakarta climate data with latitude coordinates of $6^{\circ} 20^{\prime} \mathrm{S}$, longitude $106^{\circ} 82^{\prime}$, and an altitude of 10 meters. The source of it is a data file in an Energy Simulation Training workshop organized by GBCI (Saud, 2012). This climate data was chosen because it is recognized by EnergyPlus. It is a typical climate data compilation over a period of 30 years (1980-2008) called typical meteorological year (TMY) consisting of records of 8760 hours of climate data.

\section{Envelope Design of Central Building}

Based on Jakarta Governor Regulations, it is necessary to design building envelopes to a certain specification in order to achieve an OTTV of 45 $\mathrm{W} / \mathrm{m}^{2}$. The glass used in the model is Stopsol Supersilver Green $8 \mathrm{~mm}$. It was chosen because it is one of the best types of glass. Based on Stopsol Brochure, it has an solar heat gain coefficient (SHGC) of 0,404; $\mathrm{U}$-value of $5,6 \mathrm{~W} / \mathrm{m}^{2} \mathrm{~K}$, and Visible Transmittance of $44 \%$. Building wall material used in the model is Hebel-block with layers of plaster-wall on the outside and inside. Construction of this wall has a U-value of $1.231 \mathrm{~W} / \mathrm{m}^{2} \mathrm{~K}$. Selection of this type of glass and wall material sets the WWR at $40 \%$. This combination obtained an OTTV value for the central building of $44.24 \mathrm{~W} / \mathrm{m}^{2}$ for an orientation of $0^{\circ}$ and at 44.69 $\mathrm{W} / \mathrm{m}^{2}$ for a $45^{\circ}$ orientation.

\section{Surrounding Building}

The surrounding buildings were modeled as a detached shading group, being a $3 \times 3$ block on the grid pattern divided into two parts, the central block and the surrounding blocks. The central block acts as a focus, while the other eight blocks (purple colour) act as surrounding buildings (Figure 1).

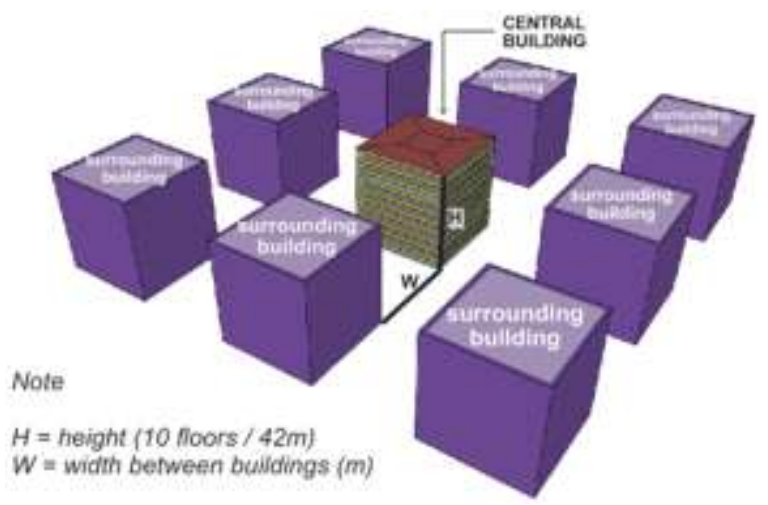

Fig. 1. Modeling of Central Building and Surrounding Buildings

To determine the effect of the thermal performance of the central building, the surrounding build- ings were made using several variations of building envelope design and varying the distances between buildings. The building envelope design consisted of several variables such as glass percentage, glass reflectance and wall reflectance, while the distances between buildings were formulated in height/width ratio (H/W ratio).

Tabel 1. Surrounding Building Variables

\begin{tabular}{ll}
\hline \multicolumn{1}{c}{ Variables } & Range \\
\hline Glass percentages & $40 \%-100 \%$ \\
Glass reflectance & $0.03-0.65$ \\
Wall reflectance & $0.2-0.65$ \\
H/W ratio & H/W $2.7-$ H/W 1.0 \\
\hline
\end{tabular}

Table 1 shows the surrounding building variables. The glass percentage value is in the range of $40 \%$ to $100 \%$. Glass reflectance value is based on the IGDB (International Glazing Data Base). Wall reflectance value describes the wall surface color. The brighter the color, the greater the value of the wall reflectance, whereas the $\mathrm{H} / \mathrm{W}$ ratio is determined by the distances between the buildings that have been ruled by the Jakarta government.

\section{Thermal Simulation}

Analysis was focused on Jakarta city using local climate data. The building thermal performance was calculated through OTTV parameters based on the effects of surrounding building variables. The differences in OTTV values were then described using an incident solar radiation simulation.

The effectiveness level of the surrounding buildings on the building's thermal performance was measured by comparing the shadowing effect of surrounding buildings at any $\mathrm{H} / \mathrm{W}$ ratio with the shadowing effects of shading elements on the condition of stand-alone buildings. Shadowing effect can be analysed from the amount of solar radiation received by the central building envelope. The shading devices used for comparison were of the horizontal shading type, the widths of which were: $0,3 \mathrm{~m} ; 0,6 \mathrm{~m} ; 0,9 \mathrm{~m}$; and $1,2 \mathrm{~m}$. Figure 2 and Figure 3 illustrate the comparison of shadowing effects based on horizontal shading and variation of $\mathrm{H} / \mathrm{W}$ ratios.
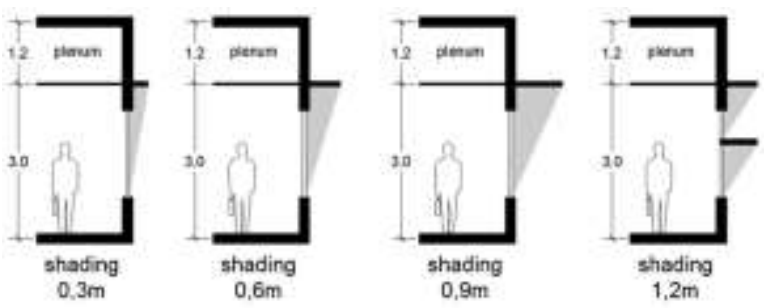

Fig. 2. Shadowing Illustration of Shading Device on Typical Floor of 'Stand-alone' Building Condition 


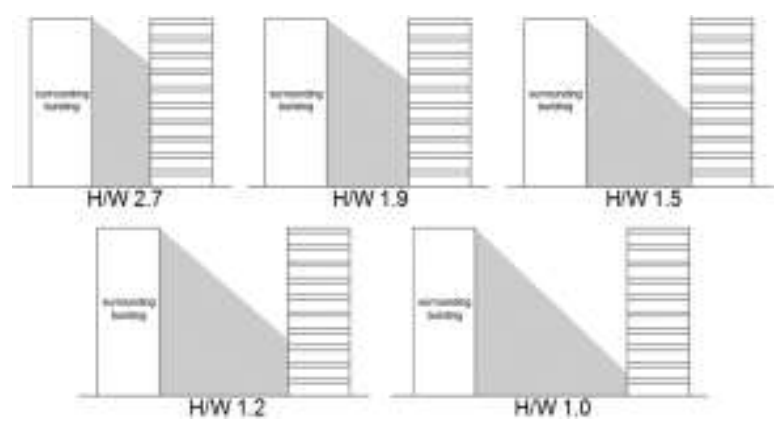

Fig. 3. Shadowing Illustration of the Surrounding Buildings

\section{RESULTS AND DISCUSSION}

\section{Efficiency Level of the Surrounding Buildings to the Thermal Performance}

In this section, the OTTV value of the central building is measured based on the surrounding building variables. These variables are: glass percentage, with a range of $40 \%-100 \%$; glass reflectance with a range of $0,03-0,65$; wall reflectance with a range of $0,2-0,65$ and $\mathrm{H} / \mathrm{W}$ ratio with a range of 2,7-1,0.

Although it is not significant, the envelope of surrounding buildings affects the variation of the central building OTTV value. At H/W 2,7, the glass percentage effect is $47-54 \%$, the glass reflectance effect is $46-52 \%$, while wall reflectance effect is $47-$ $53 \%$. From the range of thermal effects obtained, it can be concluded that the changes in the components of the surrounding building envelope affect the thermal calculation by only $0 \%$ to $8 \%$ at $\mathrm{H} / \mathrm{W} 2,7$. The best conditions are obtained when the surrounding buildings have a glass percentage of $100 \%$, glass reflectance of 0,03 or a wall reflectance of 0,2 at $\mathrm{H} / \mathrm{W}$ 2,7 . By varying these values, the OTTV of the central building will be slightly increased.

The OTTV of the central building, when based on the $\mathrm{H} / \mathrm{W}$ ratio has greater variations than when based on surrounding building envelopes. The best conditions are obtained with an $\mathrm{H} / \mathrm{W}$ ratio of 2,7 or at the shortest distance between the buildings (Figure 4). The $\mathrm{H} / \mathrm{W}$ ratio in the biggest range to the smallest gives an OTTV difference of 12,4 to $13,9 \mathrm{~W} / \mathrm{m}^{2}$. This is greater than the previous result of OTTV calculation, based on the surrounding building envelope, which had a range of only 1 to $2 \mathrm{~W} / \mathrm{m}^{2}$. The H/W ratio takes effect at 51-20\% compared with the central building OTTV in a stand-alone condition. This percentage measurement is taken with a $\mathrm{H} / \mathrm{W}$ of 2,7 to $\mathrm{H} / \mathrm{W} 1,0$.

The OTTV value based on each variable is compared with a basecase to determine the effect of each variable on the central building's thermal performance. The basecase condition is assumed to be the common high rise building condition in a dense urban environment, particularly in relation to the building envelope and the distance between the buildings.

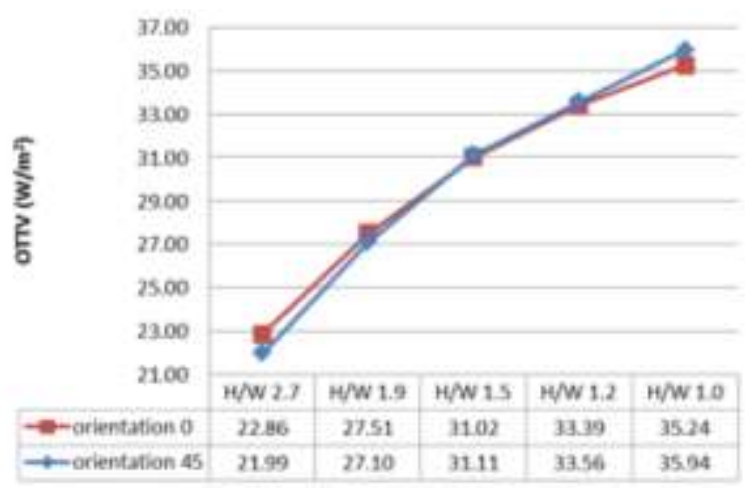

Fig. 4. OTTV Value Based on the H/W Ratio

The glass percentage on the basecase condition was set at $100 \%$, assuming a curtain wall condition in surrounding building façades. The glass reflectance was set at 0,24 assuming that the buildings use Stopsol Supersilver Green $8 \mathrm{~mm}$ glass type, which is one of the best glass types, having an SHGC value of 0,404 . The use of bright paint colors with a reflectance value of 0,5 was assumed for the walls of the buildings, while the $\mathrm{H} / \mathrm{W}$ ratio was set at 2,7 assuming the high density of buildings in Jakarta. The simulation results show that the central building OTTV in the basecase condition was $21,13 \mathrm{~W} / \mathrm{m}^{2}$ for an orientation of $0^{0}$ and $20,81 \mathrm{~W} / \mathrm{m}^{2}$ for an orientation of $45^{\circ}$.

OTTV value changes occurred in three conditions based on the variables of each of the surrounding buildings. (Figure 5) shows the OTTV value based on the surrounding building variables in three conditions compared with the basecase. The OTTV value based on the $\mathrm{H} / \mathrm{W}$ ratio has the graph which shows the most significance compared to the others. This indicates that varying the H/W ratio provides the greatest influence on the changes in the OTTV value of the central building. Meanwhile, other variables such as in the glass percentage, glass reflectance and wall reflectance produce lesser effects. This supports the research conducted by Han and Taylor (2015) which explained that the distance between the buildings provides greater thermal impact than the reflective element of the surrounding building envelope.

\section{The Shading Effectiveness of the Surrounding Buildings on Thermal Performance}

The previous simulation showed that the H/W ratio is the most influential of the variables affecting building thermal performance. In this section, the factors of the glass or building walls of surrounding buildings are ignored in the thermal calculation. 


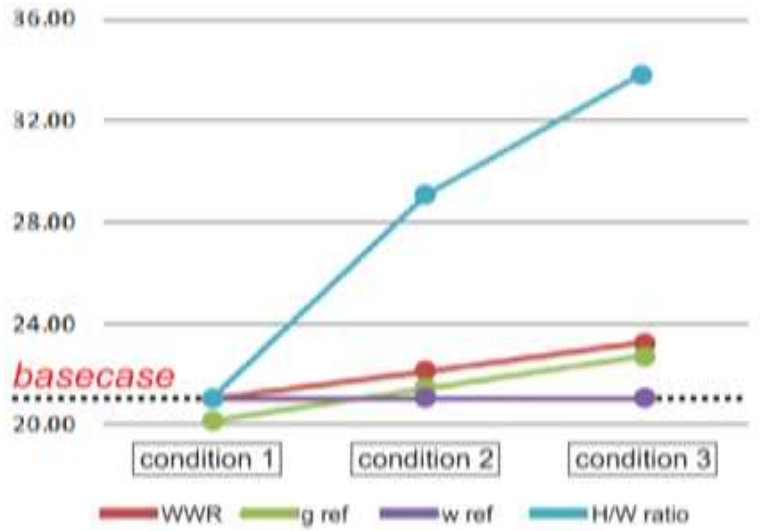

Fig. 5. OTTV Based on Changing Surrounding Building Variables Compared to Basecase Conditions (orientation $\left.0^{\circ}\right)$

The $\mathrm{H} / \mathrm{W}$ ratio variances were then analyzed for shading effectiveness on the central building. It can be seen through the incidence solar radiation, especially from direct and diffuse solar radiation. Both of which have greater radiation intensity compared to other reflected radiation. The existence of surrounding buildings at any $\mathrm{H} / \mathrm{W}$ ratio will act as a shading element/shader from incoming radiation. The shadowing effects of surrounding buildings based on the $\mathrm{H} / \mathrm{W}$ ratio were compared with the shading effect on the stand-alone building. The shading elements were assumed to be of the horizontal shading type with several widths. Table 2 shows the reduction of incidental radiation, due to the shading effect, compared with the condition of a stand-alone building without shading in the Western orientation.

Tabel 2. Shading Effect of the Shading Device on Incident Radiation in Western Orientation

\begin{tabular}{cc}
\hline Shading Width & Incident Radiation Reduction \\
\hline $0,3 \mathrm{~m}$ & $13,8 \%$ \\
$0,6 \mathrm{~m}$ & $23,6 \%$ \\
$0,9 \mathrm{~m}$ & $31,4 \%$ \\
$1,2 \mathrm{~m}$ & $38,0 \%$ \\
\hline
\end{tabular}

Figure 6 shows the incident solar radiation based on $\mathrm{H} / \mathrm{W}$ ratio on the Western orientation that becomes less at lower floor levels because of the smaller solar angle there. The decreasing incident solar radiation in each floor is then compared with the base-design.

Table 3 shows the reduction of radiation at each level based on $\mathrm{H} / \mathrm{W}$ ratios compared with the base design on the Western orientation. It also shows the particular floors which receive a shadowing effect equal to the shading effect as shown in Table 2 . The blue table illustrates the floors that have a decrease in radiation greater than $38 \%$, equal to $1,2 \mathrm{~m}$ width of shading. The orange table illustrates the floors that have a decrease in radiation greater than $31,4 \%$, equal to $0,9 \mathrm{~m}$ width shading. The purple table illustrates the floors that have a decrease in radiation greater than $23,6 \%$, equal to $0,6 \mathrm{~m}$ width shading. While the green table illustrates floors that have a decrease in radiation greater than $13,8 \%$, equal to $0,3 \mathrm{~m}$ width shading.

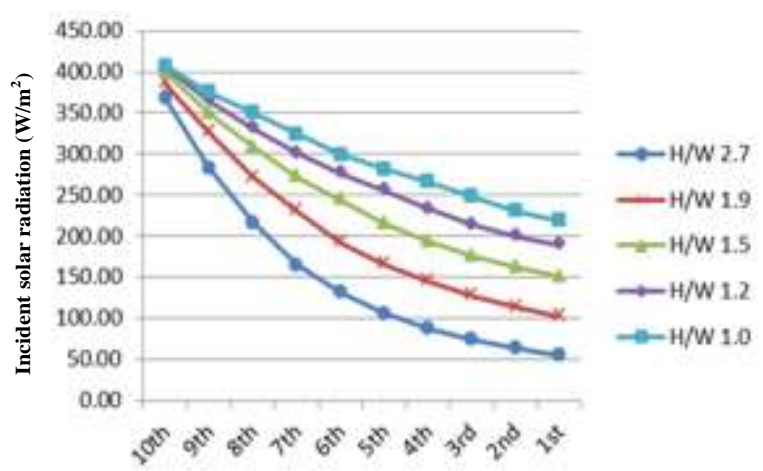

Fig. 6. Incident Solar Radiation on the Western Orientation

Tabel 3. The Reduction of Incident Radiation each Floor Based on H/W Ratio (Western orientation)

\begin{tabular}{|c|ccccc|c|}
\hline & H/W 2.7 & H/W 1.9 & H/W 1.5 & H/W 1.2 & H/W 1.0 \\
\hline 10th & $-10.70 \%$ & $-6.28 \%$ & $-3.05 \%$ & $-1.43 \%$ & $-1.16 \%$ \\
\hline 9th & $-31.20 \%$ & $-20.71 \%$ & $-15.14 \%$ & $-11.29 \%$ & $-8.82 \%$ \\
\hline 8th & $-47.34 \%$ & $-34.06 \%$ & $-25.24 \%$ & $-19.55 \%$ & $-14.98 \%$ \\
\hline 7th & $-59.78 \%$ & $-44.00 \%$ & $-33.97 \%$ & $-26.89 \%$ & $-21.25 \%$ \\
\hline 6th & $-67.97 \%$ & $-53.19 \%$ & $-40.70 \%$ & $-32.88 \%$ & $-27.21 \%$ \\
\hline 5th & $-74.22 \%$ & $-59.67 \%$ & $-47.76 \%$ & $-37.86 \%$ & $-31.53 \%$ \\
\hline 4th & $-78.72 \%$ & $-64.71 \%$ & $-53.05 \%$ & $-43.37 \%$ & $-35.41 \%$ \\
\hline 3rd & $-81.84 \%$ & $-69.01 \%$ & $-57.29 \%$ & $-48.13 \%$ & $-39.65 \%$ \\
\hline 2nd & $-84.34 \%$ & $-72.45 \%$ & $-60.57 \%$ & $-51.44 \%$ & $-43.87 \%$ \\
\hline 1st & $-86.43 \%$ & $-75.03 \%$ & $-63.52 \%$ & $-54.05 \%$ & $-46.77 \%$ \\
\hline
\end{tabular}

The shading comparison generates an effectiveness point which describes the optimal limit of the shading of surrounding buildings when compared with shading elements at a certain width. The effectiveness is then illustrated in the effective shadow angle formed by the edge of the surrounding building to the effectiveness point. Figure 7 shows the effective shadow angle based on an $\mathrm{H} / \mathrm{W}$ ratio in a Western orientation. For example, at an $\mathrm{H} / \mathrm{W}$ of 2,7 , the use of $1,2 \mathrm{~m}$ shading is not required until the 8th floor based on the angle. At a smaller angle, the shading effects will be reduced to match the effective shadow angle of less than $1,2 \mathrm{~m}$. The effective shadow angle in each side can be varied greatly depending on the $\mathrm{H} / \mathrm{W}$ ratio and the shading element used as a comparison. The effective shadow angle can be used in building facade design considerations. The use of shading elements as shader systems can be minimized without reducing the thermal performance of the building because it has responded to the existence of surrounding buildings (Figure 8). 


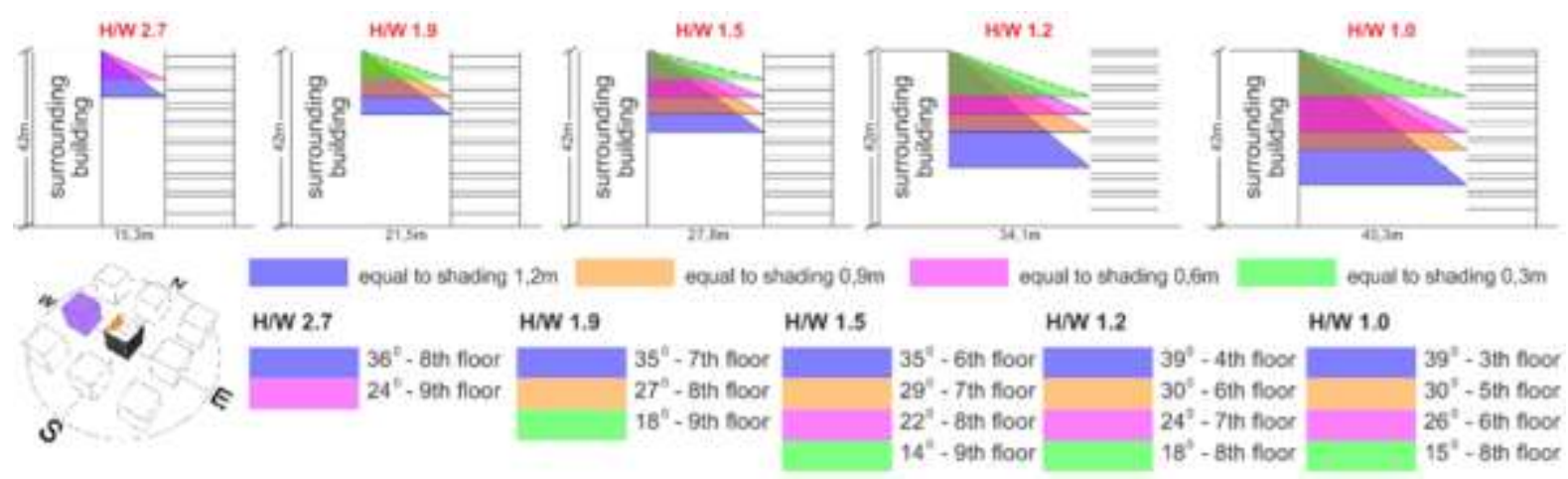

Fig. 7. The Effective Shadow Angle Based on the H/W Ratio (Western orientation)
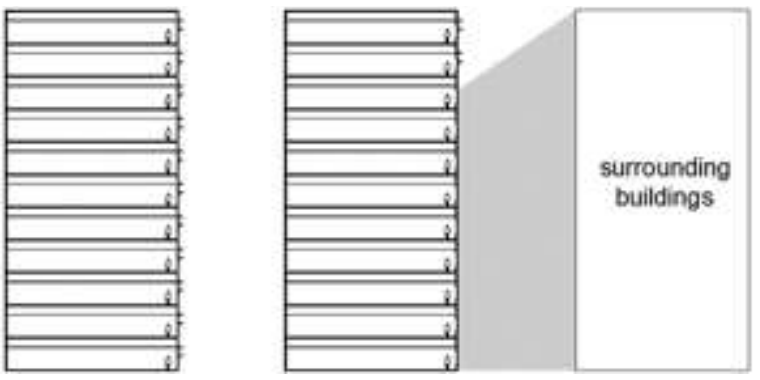

Fig. 8. The Use of Effective Shadow Angle for Minimizing the Use of 1,2 $\mathrm{m}$ Shading up to 8th floor (right) Compared to the Condition of Shadowing in Stand-alone Building (left)

\section{CONCLUSION}

The influence of the surrounding buildings has implications for the engineering of the building envelope to achieve a more favorable composition related to the thermal performance, such as the expansion of the openings or the use of more efficient glass types. In Indonesia, the intensity of solar radiation can have an impact on high building energy, mainly due to the cooling load. The shadowing effects of surrounding buildings could solve the problem of air conditioner over-capacity.

The results showed that the presence of surrounding buildings can really affect building thermal performance. At an $\mathrm{H} / \mathrm{W}$ of 1,0 the surrounding buildings have a thermal impact of $20 \%$ compared to a stand-alone building. While at an $\mathrm{H} / \mathrm{W}$ of 2,7 the surrounding buildings effect goes up to $51 \%$. The best thermal condition at any $\mathrm{H} / \mathrm{W}$ ratio is achieved when the surrounding buildings have a glass percentage of $100 \%$; glass reflectance of 0,03 ; or wall reflectance of 0,2 .

The building envelope affected by the shadowing effect of surrounding buildings should be considered by architects to design more effective building envelopes. The comparison method is needed to simplify the shading effectiveness of the surrounding buildings. The shading effect of surrounding buildings is compared to the shading effects of shading devices in a 'stand-alone' building condition. At an $\mathrm{H} / \mathrm{W}$ ratio of 1,0 the shading effect of the surrounding building will be equal to $1,2 \mathrm{~m}$ shading with an effective shadow angle greater than $42^{\circ}$. While at an $\mathrm{H} / \mathrm{W}$ of 2,7 the shading effect of the surrounding building will be equal to $1,2 \mathrm{~m}$ shading with an effective shadow angle of more than $36^{\circ}$. For example in the case of an $\mathrm{H} / \mathrm{W}$ of 2,7 the building doesn't require $1,2 \mathrm{~m}$ shading up to the 8th floor. The effective shadow angle on each side can vary greatly depending on the $\mathrm{H} / \mathrm{W}$ ratio and the shading used for comparison (Figure 9).

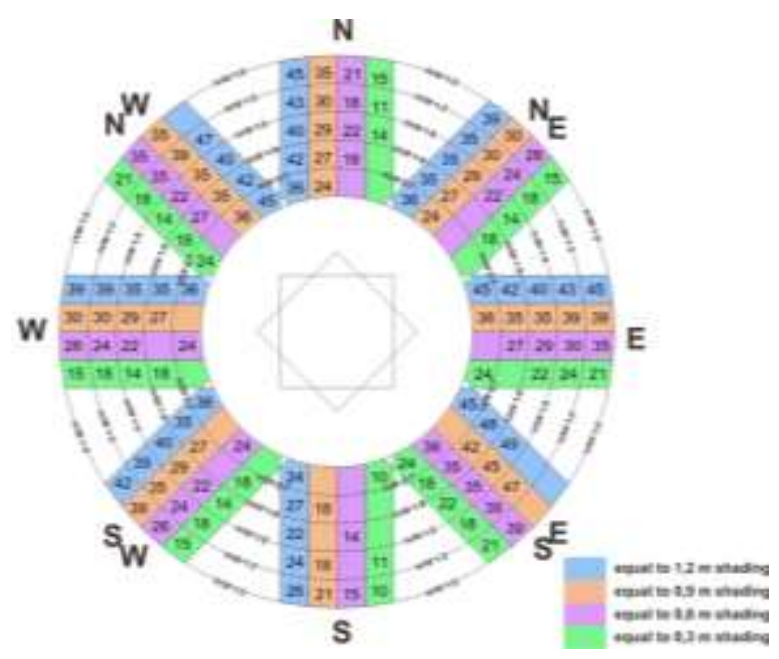

Fig. 9. The Effective Shadow Angle on each Side Based on H/W Ratios

The effectiveness levels gained from this comparison can be a reference for architects in designing building envelope that take into consideration the presence of surrounding buildings. This approach is essential to minimize the construction costs of highrise building through more effective building envelopes. Hence, the study contributes to the development of building performance analysis trough thermal indicator. The study recommends further study on the 
relationship between thermal performance and daylighting in a dense urban environment condition. The further study will be important to find the optimization that can be achieved through the thermal calculation and the daylighting calculation.

\section{ACKNOWLEDGMENT}

This paper is a part of the author's thesis, in Gadjah Mada University of Yogyakarta. For that reason, the author would like to express his gratitude to all of those supporting this study. He also would like to say thank to his colleagues from PT. Desain Performa Energi who provided insight and expertise that greatly assisted the research. The author also expresses his big thank to promoter and co-promoters.

\section{REFERENCES}

Allegrini, J., Dorer, V. \& Carmeliet, J. (2015). Influence of morphologies on the microclimate in urban neighbourhoods. Journal of Wind Eng. Ind.Aerodyn, 144, 108-117.

Andersen, J.S., \& Sattrup, P. (2011). The urban canyon and building energy use: Urban density versus daylight and passive solar gains. Energy and Buildings, 43, 2011-2020.

Ascione, F. et al. (2013). Analysis and diagnosis of the energy performance of buildings and districts: Methodology, validation and development of Urban Energy Maps. Cities, 35, 270-283.

Granadeiro, V., Duarte, J.P., Correia, J.R., \& Leal, V.M. (2013). Building envelope shape design in early stages of the design process: Integrating architectural design systems and energy simulation. Automation in Construction, 32, 196-209.

Hachem, C., Athienitis, A., \& Fazio, P. (2012). Evaluation of energy supply and demand in solar neighborhood. Energy and Buildings, 49, 335-347.

Han, Y., \& Taylor, J.E. (2015). Disaggregate Analysis of the Inter-Building Effect in a Dense Urban Environment. Energy Procedia, 75, 1348 $-1353$.

Han, Y., Pisello, A.L., \& Taylor, J.E. (2015). Toward mitigating urban heat island effects: Investigating the thermal-energy impact of bio-inspired retro-reflective building envelopes in dense urban settings. Energy and Buildings, 102, 380-389.

Kirimtat, A., Koyunbaba, B., Chatzikonstantinou, I., \& Sariyildiz, S. (2016). Review of simulation modeling for shading devices in buildings. Renewable and Sustainable Energy Reviews, 53, 23-49.

Kwong, Q.J., \& Ali, Y. (2011). A review of energy efficiency potentials in tropical buildings Perspective of enclosed common areas. Renewable and Sustainable Energy Reviews, 15, 45484553.

Lee, K.S., Lee, J.W., \& Lee, J.S. (2016). Feasibility study on the relation between housing density and solar accessibility and potential uses. Renewable Energy, 85, p.749-758.

Marique, A.F., \& Reiter, S. (2014). A simplified framework to assess the feasibility of zeroenergy at theneighbourhood/community scale. Energy and Buildings, 82, 114-122.

Samuelson, H., Claussnitzer, S., Goyal, A., Chen, Y., \& Romo-Castillo, A. (2016). Parametric energy simulation in early design: High-rise residential buildings in urban contexts. Building and Environment, 101, 19-31.

Sanaieian, H., Tenpierik, M., Linden, K.V., Seraj, F.M., \& Shemrani, S.M. (2014). Review of the Impact of Urban Block Form on Thermal Performance, Solar Access and Ventilation. Renewable and Sustainable Energy Reviews, 38, 551-560.

Saud, M.I. (2012). Pengaruh Konfigurasi Window to Wall Ratio, Solar Heat Gain Coefficient dan Orientasi Bangunan terhadap Kinerja Termal Selubung Bangunan, Yogyakarta: Universitas Gadjah Mada.

Shrader, H., \& Sayyed, A. (2012). Financing Climate Change Mitigation in the Building Sector.

Srebric, J., Heidarinejad, M., \& Liu, J. (2015). Building neighborhood emerging properties and their impacts on multi-scale modeling of building energy and airflows, Building and Environment, 91, 246-262.

Steiner, F.R., \& Butler, K. (2007). Planing and Urban Design Standards, New Jersey: John Wiley \& Sons, Inc. 